\title{
UNIVERSIDAD ILUSTRADA NEOGRANADINA E INDEPENDENCIA DE COLOMBIA (1810 - 2010)
}

\author{
Fernando Betancourt Serna ${ }^{1}$ \\ Universidad de Sevilla, Sevilla- España \\ Grupo de Investigación HISULA \\ purisalamanca@hotmail.com
}

Recepción: 30/04/2010

Evaluación: 05/05/2010

Aceptación: 01/06/2010

Artículo de Revisión

\section{RESUMEN}

El autor revisa la común opinión según la cual el intendente D. Juan Francisco Gutiérrez de Piñeres en 1779 dio marcha atrás en la reforma universitaria ilustrada del fiscal D. Francisco Antonio Moreno y Escandón en 1774 en el Nuevo Reino de Granada (Colombia). Eso es cierto en relación con el plan de estudios de filosofía y teología. No así en relación con el plan de estudios de jurisprudencia. En efecto, los dos ilustrados, el neogranadino y el castellano, no sólo mantuvieron el plan de estudios de jurisprudencia de 1774, sino que, además, cediendo sutilmente en aquellos planes de filosofía y teología para «volver al método de antes», es decir, el escolástico -en franca decadencia-, añadieron la asignatura de Derecho público, natural y de gentes, adoptando como manual la obra de J. G. Heinnecio (1681 - 1741), «Elementa iuris naturae et gentium» (1738); autor incardinado en la corriente europea del derecho natural racionalista y, por tanto, pieza fundamental en las ideas liberales. En las pocas universidades de la monarquía española que la habían introducido fue abolida por real orden de 31 de julio de 1794 y ejecutada en el Nuevo Reino de Granada al año siguiente. Así pues, durante quince años aproximadamente los juristas peninsulares y neogranadinos se formaron en los ideales políticos de la Ilustración. Por tanto, demasiado tarde para desactivar, tanto en la Península como en el Nuevo Reino de Granada, esa «carga de efecto retardado». De ellos, 28 neogranadinos cayeron fusilados en la guerra de independencia de Colombia. Perdió así el naciente estado-nación su dirigencia jurídico política de primera línea. Circunstancia absolutamente determinante en sentido negativo para el posterior desarrollo político de la sociedad colombiana.

Palabras clave: Reforma universitaria, Independencia de Colombia, Cátedra de Derecho público, natural y de gentes, Cátedra de Derecho real (ius patrium), Juristas Ilustrados Neogranadinos.

1 Doctorado en Derecho de la universidad de Navarra- España, actualmente se desempeña como profesor de la universidad de Sevilla y es miembro del grupo de Investigación Historia y Prospectiva de la Universidad Latinoamericana - HISULA. 


\title{
ENLIGHTENED NEOGRANADIAN UNIVERSITY AND INDEPENDENCE OF COLOMBIA (1810 - 2010)
}

\author{
Fernando Betancourt Serna \\ Universidad de Sevilla, Sevilla- España \\ HISULA Research Group \\ purisalamanca@hotmail.com
}

\begin{abstract}
The paper reviews the communis opinio by which the intendente D. Juan Francisco Gutiérrez de Piñeres blocked in 1779 the university reform that had been passed by the fiscal D. Francisco Antonio Moreno y Escandón in 1774 in the Nuevo Reino de Granada (Colombia). This is true regarding the Philosophy and Theology curricula, but not quite so regarding Law. As a matter of fact, the two enlightened politicians, the Neogrenadean and the Castillian not only kept the Law curriculum of 1774, but also, in the line of modifying the Philosophy and Theology curricula in orden to go back to the old system -the Scholastic methodology-, that at the time was in clear decadency, added a new subject, Public Law, Natural Law and Ius gentium, following the account made by Heinnecius (1681 - 1741) in his book "Elementa iuris naturae et gentium" (1738); Heinnecius was an author belonging to the European movement that was defending the understanding of Natural Law through the human reasoning, and therefore a propugnant of te new liberal ideas. In the few Spanish universities that had introduced the reform, it was abolished by Royal Decree of 31st of July of 1794, applied one year later in the Nuevo Reino de Granada. Therefore, during fifteen years the Castillian and Neogrenadean lawyers were exposed to the liberal ideas of underlying the Enlighment. And therefore, too late to deactivate that time-bomb in both sides of the Atlantic. Of those lawyers, 28 from New Grenade were executed at the time of the war of independence in Colombia. The consequence was that newly independent republic lost a portioned of their-trained people, a curcumstance that had a negative influence later on the development of the political process in the Colombian society.
\end{abstract}

Key words: University reform, independence of Colombia, chair of public law of nature and nations, chair of real law (ius patrium), Lawyers Granadans Illustrated. 


\section{INTRODUCCIÓN}

Este año 2010 es conmemorativo de la independencia de Colombia y de otras nobles naciones hispanoamericanas. Como colombiano y universitario de profesión no puedo dejar de adherirme a dicha efeméride con estas breves páginas que tienen por finalidad destacar la aportación de la universidad ilustrada neogranadina a esa gesta de independencia -especialmente dura en Colombia- de la madre patria. Al mismo tiempo someto a la consideración de los estudiosos colombianos en particular mi teoría revisionista sobre el status quaestionis en relación con la reforma involutiva de D. Juan Francisco Gutiérrez de Piñeres en 1779 a la reforma universitaria ilustrada neogranadina de D. Francisco Antonio Moreno y Escandón, de 1774. En efecto, resumidamente la communis opinio es la siguiente: en su calidad de Intendente del Nuevo Reino de Granada aquél llegó con el objetivo, entre otros, de dar marcha atrás en la reforma universitaria ilustrada de éste. Es cierta pero relativamente; si no es debidamente matizada dentro del contexto más general de la política del gobierno de D. Carlos III en el último decenio de su vida lleva a conclusiones erróneas.

\section{Creación y dotación de la cátedra de Derecho Público, Natural y de Gentes en el Nuevo Reino de Granada [Colombia] en 1779}

El primer plan ilustrado de estudios de jurisprudencia para una universidad de la monarquía española fue el de D. Pablo de Olavide para la Universidad de Sevilla, de 22 de agosto de 1769. ${ }^{2}$ En relación con el Derecho real o patrio (ius patrium) dicho plan dice lo siguiente:

Otro no menor olvido padece el estudio del Derecho Nacional, que no se enseña ni estudia de modo alguno. Es verdad que en el día fuera muy dificil emprenderlo, porque carecemos de códigos de leyes ordenadas y seguidas por principios, y en forma de sistema para poder tratar doctrinal-mente de sus explicaciones $e$ inteligencia. Así, entre tanto que se forma, es indispensable hacer un estudio serio del Derecho Civil de los Romanos, que, aunque carece entre nosotros de toda autoridad externa, se ha hecho necesario para saber las reglas y principios que constituyen el fondo de nuestras leyes, y sin cuya instrucción no podría entenderse. Este método produce no pocos inconvenientes, porque preocupados los estudiantes de aquellas máximas (que en mucha parte ha hecho opuestas a

2 Las restantes reformas ilustradas, por orden cronológico, fueron las siguientes: Universidad de Salamanca (1771), Universidad de Valladolid (1771), Universidad de Alcalá de Henares (1772), Universidad de Santiago de Compostela (1772), Universidad de Oviedo (1774), Universidad de Santo Tomas de Aquino y Colegios Mayores de San Bartolomé y Nuestra Señora del Rosario de Santafé de Bogotá (1774 - reforma 1779), Universidad de Granada (1776), Universidad de Zaragoza (1776 - reforma 1786), y Universidad de Valencia (1786).

Rhela. Vol. 14. Año 2010, pp. 83 - 99 
nuestra constitución la vicisitud de los tiempos y de las costumbres), dificilmente las sacuden, y aun se esfuerzan a sostenerlas muchas veces con violencia y repugnancia de las leyes patrias, haciendo así depender nuestro Derecho del extraño y que éste sea el principal estudio de los profesores. Para cortar este abuso en su raíz repetimos que es necesaria la formación de un nuevo Código Nacional. Esta es la obra digna de la ilustración del Consejo y deseada en toda la nación, por lo que no dudamos se piense seriamente en ella, como medio de poner en todo el orden y esplendor que se debe en una ciencia que interesa la vida, honor y hacienda de los vasallos. ${ }^{3}$

Planteada la anterior premisa, el autor del plan, procediendo con lógica en relación con el Derecho real o patrio, dispone lo siguiente:

No estudiándose, como hemos dicho, el Derecho Nacional en las Universidades, quisiéramos aun en este Plan provisional ocurrir a una omisión de tanta consecuencia. A este fin, nos parecía se mandase que los catedráticos, al tiempo de explicar cada texto de Instituta, expusiesen las leyes concordantes de nuestro Derecho patrio, deteniéndose, por consiguiente, más en aquellos párrafos es cuya doctrina se observa actualmente en nuestros tribunales por ser conforme a nuestras leyes y pasando a la ligera por los demás que carecen de esta recomendación; por este medio se conseguirá que los estudiantes adquieran con el Derecho Civil de los Romanos alguna tintura del Real Español, se acostumbren a manejar sus propias leyes y a conocer su autoridad y preferencia, y se suplirá en alguna parte a un estudio que debería ser el principal, pero que no es posible hacerlo en el día metódicamente sin un nuevo código o Instituta nacional. ${ }^{4}$

En relación con el mismo aspecto del estudio universitario del derecho real o patrio (ius patrium) para el Nuevo Reino de Granada, veamos ahora el plan de estudios de jurisprudencia de D. Francisco Antonio Moreno y Escandón, de 22 de septiembre de 1774, para los Colegios Mayores de San Bartolomé(1605) y Nuestra Señora del Rosario (1653). Dice el fiscal Moreno y Escandón en el prólogo ha dicho plan de jurisprudencia:

Siendo por muchos títulos indispensable la instrucción en el derecho de los Romanos y no habiendo facultades para establecer un curso de jurisprudencia civil separado de la canónica, podrá ocurrirse a este inconveniente fijándose un curso que abrace a uno y otro derecho que consuma el término de cinco

\footnotetext{
3 OLAVIDE, Pablo De. Plan de estudios universitarios [1769], en (Ed.) F. AGUILAR PIÑAL. (1898): Plan de estudios para la Universidad de Sevilla. Sevilla. Estudio preliminar por Francisco Aguilar Piñal. $2^{\mathrm{a}}$ edición, revisada y actualizada, pp. $71-156$, concretamente en p. 131 s., y (Ed.) J. MARCHENA FERNÁNDEZ, Juan. (2001) El tiempo ilustrado de Pablo de Olavide. Vida, obra y sueños de un americano en la España del s. XVIII pp. $145-219$. 4 OLAVIDE, Pablo De. (2001): Plan de estudios universitarios [1769]. (Sevilla ${ }^{2} 1989$ ) 134, pp. $196-197$.
} 
años que se estima suficientes para que los jóvenes logren sacar aquellos primeros principios y elementos, con que puedan después consumarse en la facultad, pues nadie ignora no sólo la importancia del conocimiento del derecho civil, adoptando (sic = adoptado) por el general consentimiento de las naciones, sino también su conducen-cia para la inteligencia del derecho patrio y canónico, no pudiéndose éstos penetrar debidamente sin el socorro de aquél, por lo que no parecerá impropio unirlos, para que explicados oportunamente, saquen los discípulos aquel sólido aprovechamiento que pueda adquirirse en las es-cuelas para llegar después a la perfección. ${ }^{5}$

Planteada la anterior premisa, también con la misma lógica ilustrada, el fiscal Moreno y Escandón dispone en su plan de jurisprudencia en relación con el Derecho real o patrio (ius patrium) ${ }^{6}$

Primero y segundo año de jurisprudencia

En estos dos primeros años, después de instruir el catedrático a sus discípulos de los principios más esenciales de la historia relativa al derecho de los Romanos, sus ritos y autoridades de los tribunales y Magistrados de que traen origen sus leyes, explicarán los cuatro libros de la Instituta de Justiniano, dividiéndola en dos libros por año con la precisa obligación, no sólo de omitir o pasar a la ligera, los títulos o párrafos menos importantes, sino también de exponer las leyes reales concordantes, su conexión y nervio; valiéndose para la explicación de lo primero de los comentarios de Arnoldo Vinio, ${ }^{7}$ y notas de Heinecio, ${ }^{8}$ y para lo segundo podrá auxiliarse de la

5 MORENO Y ESCANDÓN, Método provisional e interino de los estudios que han de observar los colegios de Santafé por ahora y hasta tanto que se erige universidad pública o su majestad dispone otra cosa [1774]; HERNANDEZ DE ALBA, Guillermo. (1980): Documentos para la historia de la educación en Colombia. Tomo IV [1767 - 1776]. Bogotá, Patronato Colombiano de Artes y Ciencias. Colegio Máximo de las Academias Colombianas, pp. 195 - 227; SOTO ARANGO, Diana Elvira. (2004): La reforma del plan de estudios del fiscal Moreno y Escandón 1774 - 1779. Bogotá, Rudecolombia, pp. $102-$ 139.

6 MORENO Y ESCANDÓN, Francisco Antonio. (1980): Método provisional e interino de los estudios [1774], pp. 214,124. Vid. el análisis que de dicho plan de jurisprudencia hace M. CORTES FALLA, (2003): La enseñanza del derecho romano en Colombia 1710 1826. Nueva Granada y origenes de la República. Bucaramanga 3. El plan de estudios de 1774 pp. 47 - 56, y F. BETANCOURTSERNA. (2007): La recepción del derecho romano en Colombia. Sevilla, pp. 677 - 692 - 712 - 728 .

7 Para la biografía de Arnold Vinnio, vid. R. FEENSTRA - C. J. WAAL, SeventeenthCentury Leyden Law Professors and their influence on the development of the Civil Law. A Study of Branchorst, Vinnius and Voet (Amsterdam / Oxford 1975); (Eds.) G. KLEINHEYER - J. SCHRÖDER, Deutsche und europäische Juristen (Heildelberg $\left.{ }^{4} 1996\right)$ s. v. Vinnius, Arnoldus (1588 - 1657) 516 - 517 (M.), (Ed.) M. STOLLEIS, Juristen (München 2001) s. v. Vinnius, Arnold (1588 - 1657) 653 - 654 (M. Ahsmann), y (Ed.) R. DOMINGO, Juristas universales II (Madrid / Barcelona 2004) s. v. Arnold Vinnen (Arnoldus Vinnius) [1588 $1657] 352$ - 354 (Álvaro Núñez Iglesias). Una vez expurgada por la Inquisición Española, la Instituta de Vinnio se publicó por primera vez en un país católico en Lyon (Francia) en 1707. La primera edición española es de 1724. Luego vendrían las ediciones de Sala de (Valencia 1779 / 1780) y Danvila de (Valencia de 1779 y 1786).

8 En 1726, Johann Gottlieb Heinnecio [Heinecke] $(1681$ - 1741) -profesor en Halleaprovechando una corta estancia como professor en la Facultad de Derecho de Franeker 
Instituta de Torres que refiere algunas leyes reales y podrá ilustrar en su explicación dedicándose a formar un cuaderno de apuntamientos y reflexio-nes más útiles que servirán después de auxilio, para arreglar un com-pendió metódico, digno de la luz pública, que será más apreciable trayendo siempre lo dispuesto en las Leyes de Indias ${ }^{9}$ que tuvieren alguna particularidad, que altere o varíe lo establecido en el derecho romano, y aún en muchas leyes de Castilla, Partida y otras anteriores; para que de este modo formen los estudiantes una segura, aunque no perfectamente completa idea de nuestro derecho patrio que les facilite el camino a lo forense y práctico, ejercicio de los juicios y acciones legales en que tienen mucha consonancia nuestras leyes con el derecho romano, haciéndose este estudio más fácil y oportuno por este medio que si con separación se enseñase el derecho patrio [...].

El 13 y 126 de septiembre de 1779 la junta superior de estudios del Nuevo Reino de Granada presidida -por ausencia del arzobispo-virrey D. Antonio Caballero y Góngora- por el Intendente D. Juan Francisco Gutiérrez de Piñeres, ${ }^{10}$ y con la presencia del fiscal Moreno y Escandón, reformó involutivamente el plan de estudios de 1774, excepto para el plan de estudios de jurisprudencia. En efecto, los dos ilustrados presentes en esa junta, el castellano y el neogranadino, "cediendo" en el plan de filosofía y en el de teología volviendo en ellos "al método de antes", es decir, el escolástico: La Summa theologiae de santo Tomás de Aquino y las Sententiae de Pedro Lombardo, ${ }^{11}$ no sólo lograron mantener el plan de jurisprudencia de 1774,

(Holanda), revisó el texto de los Comentarios de A. Vinnio, añadiéndole sus Recitationes, con lo cual dio más fama a la obra. Vid. (Eds.) G. KLEINHEYER - J. SCHRÖDER. (2004): Deutsche und europäische Juristen (Heidelberg ${ }^{4}$ 1996) s. v. Heineccius, Johann Gottlieb (Heinecke) [1681 - 1741) 482 (E. Busi), (Ed.) M. STOLLEIS, Juristen (München 2001) s. v. Heineccius, Johan Gottlieb [1681 - 1741]289 - 290 (K. Luig), y (Ed.) R. DOMINGO, Juristas universales II (Madrid / Barcelona) s. v. Johann Gottlieb Heinecke (Heineccius, Heinecio) [1681 - 1741] 522 - 524 (Pedro de Pablo Contreras). Vid. JUAN HEINECIO, Recitationes del Derecho Civil. Traducidas al castellano, anotadas y adicionadas considerablemente por D. Luis de Collantes Bustamante. Tercera edición. Tomos I - II (Valencia 1841). Hay $7^{\text {a }}$ edición de 1789. También tuvimos acceso a la edición de Madrid de 1855.

9 Vid. I. SÁNCHEZ BELLA. (2005): Valoración de las Recopilaciones de Indias de 1635 a 1680 (Libros I y II de León Pinelo), pp. 21 - 27.

${ }^{10}$ De noble estirpe castellana D. Juan Francisco Gutiérrez de Piñeres nace en lebeña, siendo bautizado el 10. IX. 1732, y muere antes de 1809 posiblemente en Escalona de Alberche (Toledo). Estudió durante tres años Filosofía en el Colegio de Santo Tomás de Sevilla y luego se dedicó al ejercicio de las leyes. Se recibió de abogado de la Real Audiencia de Sevilla el 20 de febrero de 1758 y en el Colegio de Abogados el 6 de marzo de 1762. El 21 de julio de 1763 fue nombrado alcalde mayor de fieles ejecutores de Sevilla y en 1764 promovido a alcalde mayor de la justicia y más tarde teniente primero del asistente de Sevilla D. Pablo de Olavide. Como tal fue una de las cinco personalidades que cooperó con Olavide en la redacción del plan de estudios para la universidad. Vid. F. BETANCOURT-SERNA, La recepción del derecho romano en Colombia (Saec. XVIII) (Sevilla 2007) Cap. IV C $\S 11$. "Reforma del plan de estudios del intendente D. Juan Francisco Gutiérrez de Piñeres, de 13 y 16 de octubre de 1779 p. $751-801$.

${ }^{11}$ Al fin y al cabo ya era una disciplina alejada de la nueva propuesta epistemológica que privilegiaba la observación y la experimentación sobre la especulación teológica. Por lo demás, los dos ilustrados también cedieron transitoriamente en la idea de sacar 
sino que, además, les "colaron" en el nuevo plan ni más ni menos que una "carga ideológica" de efecto retardado: la cátedra de Derecho público, natural y de gentes, con base en la obra de J. G. Heinecio (1681 - 1741): Elementa iuris naturae et gentium (1738). J. G. Heinecio incardinado en la corriente del derecho natural racionalista, ordenó a la vez que refundió en ciertos aspectos los planteamientos de Hugo Grocio $\left(1583\right.$ - 1645), ${ }^{12}$ Samuel Pufendorf $(1632-1694)^{13}$ y Ch. Tomasius $(1655-1728) .{ }^{14} \mathrm{Su}$ aportación fundamental, presente en la totalidad de su obra, pero explicada sobre todo en sus Elementa, consiste en el intento de descender de la teoría a la práctica: convertir el derecho natural en jurisprudencia, transformar lo ideal en aplicable y aplicado. Así, pues, Heinecio era pieza importante en la difusión de los planteamientos liberales. Por tanto, en nuestra opinión, esta "reforma" de 1779 hacía mucho más "peligrosa" la difusión de las ideas políticas de la Ilustración. No sólo esto, sino que los dos ilustrados, a los comentarios de Vinnio, añadieron sus Quaestiones selectae; mantuvieron el estudio de D. 50, 16: De verborum significatione y de D. 50, 17: De diversis regulis iuris antiqui.

\section{El Index librorum prohibitorum et expurgatorum español de 1707}

A propósito de aquellos juristas protestantes a los que hemos hecho referencia, y para evitar malentendidos, debemos poner de relieve lo siguiente. El Novissimus librorum prohibitorum expurgatorum index de $1707,{ }^{15}$ que se comenzó a preparar en tiempos del inquisidor general Diego de Valladares y se completo en el de su sucesor, Vidal Martín, recoge las obras "condenadas" y "expurgadas" entre 1640 e inicios del siglo XVIII. Dado que el Index de 1707 es el referente para el siglo XVIII -sin excluir el de 1747-, indicaremos lo siguiente. Es index porque viene organizado por orden alfabético (del nombre de pila, aunque el tomo II trae el índice por orden alfabético de apellidos) de autores "prohibidos" o "expurgados" donec

\footnotetext{
adelante el proyecto de Universidad Mayor Real y Pública para el virreinato de la Nueva Granada, siguiendo el precedente de Lima y México, cabeceras de virreinato.

12 (Ed.) G. KLEINHEYER - J. SCHRÖDER, Deutsche und europäische Juristen (Heidelberg $\left.{ }^{4} 1996\right)$ s. v. Hugo Grotius (1583 - 1645) 176 - 182 (T. Moosheimer), (Ed.) M. STOLLEIS, Juristen (München 2001) s. v. Grotius (de Groot), Hugo (1583 - 1645) 265 - 268 (R. Feenstra), y (Ed.) R. DOMINGO, Juristas universals II (Madrid / Barcelona 2004) s. v. Hugo Grocio [Huig de Groot, Grotius, Hugo el Grande] (1583 - 1645) 334 - 342 (José Antonio Corrientes).

13 (Ed.) G. KLEINHEYER - J. SCHRÖDER, Deutsche und europäische Juristen (Heidelberg $\left.{ }^{4} 1996\right)$ s. v. Samuel Pufendorf (1632 - 1694) 335 - 340 (H.), (Ed.) M. STOLLEIS, Juristen (München 2001) s. v. Pufendorf, Samuel (1632 - 1694) 520 - 522 (K. Luig), y (Ed.) R. DOMINGO, Juristas universals II (Madrid / Barcelona 2004) s. v. Samuel Pufendorf (1632 - 1694) 424 - 429 (María Isabel Ruiz Gallardón).

14 (Ed.) G. KLEINHEYER - J. SCHRÖDER, Deutsche und europäische Juristen (Heidelberg $\left.{ }^{4} 1996\right)$ s. v. Christian Thomasius (1655 - 1728) $424-431$ (H.), Y (Ed.) R. DOMINGO, Juristas universals II (Madrid / Barcelona 2004) s. v. Christian Thomasius (1655 - 1728) 471 - 476 (Francisco Carpintero - José Justo Megías Quirós).

${ }^{15}$ Index librorum prohibitorum et expurgatorum I - II (Matriti 1707)
} 
corrigatur (= mientras no se corrija, es decir, mientras no se expurgue la obra y, por tanto, indica que la prohibición es temporal, en espera de que la obra sea corregida). En relación con el comentario de A. Vinnio - publicado en 1642-, quedó cobijado en el Index de 1707, en el cual se dice expresamente: "Arnoldus Vinnius, I. C. In quatuor libros Institutionum Imperialium, Lugduni apud laurentius Anison 1666. In prima fronte operis opone Notam Auct. D opus vero cum expurgatione permissum. Lib. I tit. 9 [IJ. 1, 9: De patria potestate [ p. 56. Dele a Quamobrem concludendum, usque ad ita etiam D. Thom = Eodem lib. Tit. II [IJ. 1, 10: De nuptiis] pag. 62 dele totam pag. quae íncipit, et civilis et naturali, usque ad Non evidenter dicentium $=$ Ibiden pag. 63 dele a Ex nostra constitutione, usque ad nulli habentur = pag. 64 dele, a Speciem cognationis usque ad Vide Bezan. = pag. 71, a Coeterum nemo, usque ad Ex gradibus prohibitis = pag. 75 in tit. dele a Refellitur, usque ad Confirmari $=$ Et infra dele ab illegitime, usque ad Tum iuris consultis, inclus. $=$ In indice, verb. Nuptiae, dele a Nuptiae sine parentum, usque ad Copula, verb. Poligamia, usque ad Licita fuit..$^{16}$ Así, pues, una vez que A. Vinnio pasó por el Index expurgatorum, la industria editorial de los países católicos procedió a imprimir su famosa obra para el "consumo" interno y para su exportación. Fue lo que hizo la floreciente industria editorial francesa al año siguiente, en 1708. Por tanto, en el Index prohibitorum et expurgatorum español y en los distintos países europeos católicos y de la América católica (Iberoamérica) hay que tener mucho cuidado al indicar cuál es la edición que se "prohíbe": aquella o aquellas que no han sido "expurgadas" por el Index. En nuestra opinión, no se puede hacer una historia jurídica y cultural objetiva de esa Europa y América católicas sin tener en cuenta este aspecto: no se prohíbe la lectura y estudio de pensadores protestantes, sino que se prohíbe la lectura de esos mismos autores en ediciones que no han sido expurgadas, ${ }^{17}$ excepto, naturalmente, la opera omnia de los heresiarcas, cuya lectura y edición está radicalmente prohibida. A partir de aquella edición francesa de Lyon de 1707, "el Vinnio" se difundió por toda la Europa católica y el Nuevo Mundo. Si tenemos en cuenta la edición de Madrid de 1723 / 1724, podemos afirmar que nuestro autor se introdujo en España ya en el primer cuarto del siglo XVIII. En 1729 se publicó en Ginebra / Lyon una edición en la cual A. Vinnio también es calificado como auctor damnatus ${ }^{18}$ cum expurgatione vero permissus, seguido

\footnotetext{
${ }^{16}$ Index librorum prohibitorum I (Matriti 1707) $441-442$.

17 J. M. DE BUJANDA, Index librorum prohibitorum 1600 - 1966 (Montréal / Gèneve 2002) 923: "Vinnius (Vinnen), Arnol (1586 - 1657). Hol. Protestant. Juriconsulte. Professeur de droit romain à l'Université de Leyde. In quattuor libros institutionum imperialium commentarius academicus et forensis. Venezia, Paolo Balleoni, 1712, in $4^{\circ}, 978$ p. Roma BN. Première édition: Commentarius locupletissimus ... Leiden, Joannes Maire 1642, in $4^{\circ},[12], 1447$, [30] p. Roma, BV Donec corrig. Decr. 28 - 07 - 1721; $04-12$ - 1724".

${ }^{18}$ Por la institución del Derecho criminal romano de la damnatio memoriae, pena accesoria a la principal de muerte, fundamentalmente en el delito de perduellio o crimen maiestatis: la deshonra sobre la memoria del reo. Cuando el acusado y condenado era un magistrado procedía la anulación de los actos personales de gobierno a trevés de la
} 
de la indicación de que tratan de religión aunque se contengan errores. Se permiten, no obstante, las obras de herejes que no traten de religión, una vez que hayan sido examinadas y corregidas por la inquisición. En términos generales y en relación con las obras de derecho privado patrimonial, esas expurgaciones afectaban casi exclusivamente a la materia matrimonial y familiar. En relación con Hugo Grocio, Samuel Pufendorf y J. G. Heinecio, veamos que dice el Index prohibitorum et expurgatorum español de 1747 en relación con algunas de sus obras más representativas de cada uno de ellos, poniendo de relieve que el decreto es el de condena. Hugo Grocio: ${ }^{19}$ "Né a Delft. Hol. Protestant. Théologien. Historiograpje de Hollande. Diplomat. Juriste, appelé "Pére du droit des gens [...] De iure belli ac pacis libri tres. In quibus ius naturae et gentium: item iuris publici praecipua explicantur. Paris, Nicolas Buon, 1625, in 4a , [32], 786, [78] p. Paris BN. Decr. 04 - 02 - 1627 à 1900 [...] Opera omnia theological, in tres tomos divisa. Amsterdam, Jean Blaeu, 1769, in- fol., 3 tomes en 4 vol. Paris, BN. Decr. 10 - 05 - 1757"; Samuel Pufendorf:20 "Né a Dorfchmnitz, Saxe. All. Baron. Protestant. Jurisconsulte. Historien. Publiciste. Professeur de droit naturel à Heidelberg et à Lund $[\ldots]$ De iure natural et gentium, libri octo. Lund, A. Junghans, 1672, in- $4^{\circ}$, [20], 1227, [9] p. Wolfenbüttel, HAB. Condamnè premièrement en français: Le droit de la nature et des gens ..., avec des notes du traducteur (Trad. Jean Barbeyrac). Amsterdam, Gerrit Kuiper, 1706, in $4^{\circ}, 2$ vol. Paris, BN. Decr. $20-01$ - 1711; $04-05-1711$ [...] De officio hominis et civis juxta legem naturalem, libri duo. Lund, A. Junghans, 1673, in- $8^{\circ}, 240$ p. Paris BN. Decr. $02-08-1751$ ”, y J. Heinecio: ${ }^{21}$ "Né à Eisenberg. Thuringe. All. Protestant. Jurisconsulte. Historien du droit. Humaniste. Professeur à Halle. Conseiller du roi de Prusse [...] Elementa iuris naturae et gentium, commode auditoribus method adornata. Halle, aux dépens d'Orphanotropheus, 1738, in $8^{\circ}$, [12], 576, [24] p. Tübingen, UB. Decr. $24-$ 03 - 1743. Dans les index antérieurs à 1900 figurait la mention donec corrig."

\footnotetext{
rescissio actorum; es decir, además de la nulidad de sus actos de gobierno se "borraba su nombre de todo documento oficial". Vid. F. BETANCOURT, La "damnatio memoriae" en el Cod. Vat. Lat. 5766, en (Ed.) J. GONZÁLEZ, Roma y las provincias. Realidad administrativa e ideología imperial (Madrid 1994) 25 - 37. La damnatio memoriae procede incluso en el caso de las inscripciones epigráficas del nombre del condenado, como se verifica en A. CABALLOS RUGINO - W. ECK - F. FERNÁNDEZ, El Senadoconsulto de Gneo Pisone padre (Sevilla 1996) 124 Lín. 82 s. Vid. R. DE CASTROCAMERO, El "crimen maiestatis" a la luz del "Senatus consultum de Cn. Pisone patre (Sevilla 2000). Algún editor español de la obra de A. Vinnio también lo denomina con otra expresión relativamente frecuente, en el mismo sentido, "Vinnius castigatus".

19 J. M. DE BUJANDA, Index librorum prohibitorum 1600 - 1966 (Montréal / Gèneve 2002) s. v. Grotius, Hugo [Huig van Groot] (1583 - 1645) $408-410$.

20 J. M. DE BUJANDA, Index librorum prohibitorum 1600 - 1966 (Montréal / Gèneve 2002) s. v. Pufendorf, Samuel von $(1632-1694) 731-732$.

${ }^{21}$ J. M. DE BUJANDA, Index librorum prohibitorum 1600 - 1966 (Montréal / Gèneve 2002) s. v. Heinecius, Johann Gottlieb (1681-1741) 429.
} 
Por todo lo anterior, el plan de estudios de jurisprudencia deD. Pablo de Olavide, de 1769 , dice expresamente lo siguiente: ${ }^{22}$

Deberá, pues, dar principio por el Derecho natural, que, como hemos dicho, es el origen y fuente de todas las leyes. La dificultad consiste en señalar la obra o autor que por ahora podrá servir para la enseñanza de este derecho, porque, aunque merece la primera atención el célebre Grocio, por haber sido el corifeo de los escitores de la presente materia, trató más del Derecho Público que del Natural reduciendo su obra principalmente a las dos supremas regalías de la guerra y de la paz. El Barónde Puffendorf, aunque abrazó uno y otro derecho por reglas y principios, siguiendo el camino que halló abierto de su precursor formó una obra muy basta y dilatada que no puede enseñarse sin notas o escolios. Y, sin embargo de haberla traducido con ella en francés Juan Barbayrac, se hallan éstas prohibidas en España, por estar tinturadas de la religión de su autor, cuyo inconveniente tienen otras varias obras de escritores protestantes. Estas consideraciones nos ponen en la precisión de anteponer a las demás la obra de Juan Heinecio, intitulada Elementa juris naturae et Gentium, pues está escrita en compendio por reglas y principios, que es el método que debe observarse en las Universidades [...] Después de estos prolegómenos empezará la explicación de dichas instituciones por el comentario de Arnoldo Vinio con las notas de Heinecio, cuyo estudio ocupará dos años, que son el segundo y tercero del curso, distribuyendo en ellos por mitad los cuatro libros de la Instituta, y omitiendo todos los títulos y textos que se consideren inútiles o poco importantes, como el De nuptiis, a excepción del último párrafo, que conduce mucho para la inteligencia de la legitimación de los hijos naturales, y todos los trece títulos primeros del libro tercero, como se hace comúnmente en todas las academias y seminarios particulares $[\ldots]$.

Por tanto, doctrinal y universitariamente, si no nos equivocamos, podemos situar el origen del constitucionalismo español y neogranadino [colombiano] en la obra de Juan Heinecio. ${ }^{23}$ Por otra parte, como afirman los profesores Feenstra y Waal, ${ }^{24}$ refiriéndose a S. Vinnio, aparte Hugo Grocio con su De iure belli ac pacis (1625) no existe ningún otro jurista holandés que haya conocido tal éxito en el extranjero. En efecto, la monografía la concluyen los autores con un apartado III. Some general reflections on the use of the Works of Bronchorst, Vinnius and Voet outside the

\footnotetext{
22 OLAVIDE, Pablo de. (2001); Plan de estudios universitarios [1769]. Sevilla, pp. 132 - 133 - 195 - 196.

23 Vid. (Ed.) A. BOTERO BERNAL. (2006): Origen del constitucionalismo colombiano. Ponencias del III Seminario Internacional de Teoría General del Derecho p. 214.

${ }^{24}$ R. FEENSTRA - C. J. C. WAAL. (1975): Seventeenth-Century Leyden Professors and their influence on the development oth their Civil Law. Amsterdam / Oxford, A Study of Branchorst, Vinnius and Voet pp.83 - 109.
} 
Dutch Republic. 1. Foreing Law Students at Leyden University in the $17^{\text {th }}$ Century. 2. Influence in Scotland. 3. Influence in Germany. 4. Influence in the Southern Netherlands. 5. Influence in France. 6. Influence in Spain.7. Influence in Italy. 8. Influence in England and the Unitet States. ${ }^{25}$ 9. Influence in Africa. Ahora, objetivamente, podemos agregar otro país a esa influencia universal deArnold Vinnio, Colombia, y no sólo como mera influencia doctrinal en la universidad ilustrada neogranadina, sino también como base doctrinal para el ms.n $n^{\circ} 274$ BNC. ${ }^{26}$

Así, pues, no cabe más conclusión general que la siguiente en relación con las reformas universitarias ilustradas de las universidades españolas y neogranadina: que las resistencias filosóficas y doctrinales tuvieron una endeble y errónea argumentación y, en muchos casos, una completa falta de información. Francamente, en este aspecto resulta aleccionador el contraste con las reformas ilustradas -al menos de los estudios de derecho- de las universidades (en Estados católicos) de Viena [1365], de 1753, Praga [1347], de 1754, Insbruck [1668], de 1765, Friburgo [1457], de 1765, Trnava [Hungría 1635], de 1775 / 1779, Pavía [1361], de 1771 / 1773, Cracovia [1364], de 1777 / 1786, y Coimbra [1290], de 1772. ${ }^{27}$

$\mathrm{Al}$ "barullo" universitario de las reformas ilustradas de la península y de la Nueva Granada -problema de política interna-, vino a sumarse el más grave acontecer político de la Francia revolucionaria y sus repercusiones en España e Hispanoamérica. Fundamentalmente, la toma de la bastilla, el 14 de julio de 1789, la

25 Vid. P. STEIN, Roman Law in European History (Cambridge University Press 1999) 99 (s.): "The encyclopedic nature of Vinniu's book, cast in the familiar institutional scheme, made it a work of reference until the end of the eighteenth century. Vinnius also published a shorter version, or Notae, intended exclusively for students, that aimed to explain the Institutes, according to the best humanist ideas, but with little reference to practice. A hundred years later the short Notes were recommended by Lord Mansfiel in England as the best introduction to Roman Law for a gentleman and were real by John Adams, later the second President of the United States [1795;6-1801], when as Student at Harvard College". Vid. (Ed.) R. DOMINGO, Juristas universals II (Madrid / Barcelona 2004) s. v. William Murray, Lord Mansfield (1705 - 1793) 598 - 603 (Javier Martínez-Torrón), y s. v. John Adams (1735 - 1826) 684 - 689 (Asunción de la Iglesia).

${ }^{26}$ Vid. la transcripción y estudio del manuscrito número 274 de la Biblioteca Nacional de Colombia en F. BETANCOURT SERNA, Fernando. (2007): La recepción del derecho romano en Colombia (Saec. XVIII). Sevilla Segunda Parte. Transcripción paleográfica y traducción del Ms. $\mathrm{N}^{\circ} 274$ BNC, pp. $937-1049$.

27 Vid. F. BETANCOURT-SERNA, Fernando. (2007): Valoración histórica de las reformas de los planes de estudio de derecho en la ilustración europea, en (Coord.) $\mathrm{M}^{\mathrm{a}}$. R. LEÓN BENÍTEZ, La licenciatura de derecho en el contexto de la convergencia europea. Obra patrocinada por la Fundación El Monte y por la Cátedra Jean Monet de la Universidad de Sevilla. Bajo los auspicios de la Dirección General de Educación y Cultura de la Comisión de la Unión Europea,Valencia, pp. 25 - 72. Los estatutos anteriores de la Universidad de Coimbra fueron los de D. Felipe II de Habsburgo y Portugal, de 2. VI. 1597, reformados en 161, pero sin tocar su sustancia, por D. Francisco de Bragança. Los estatutos de 1772 -reforma ilustradafueron obra del ministro D. Sebastiâo José de Carvahlo, Marqués de Pombal (Lisboa 13. V. $1699-8$. V. 1782).

Rhela. Vol. 14. Año 2010, pp. 83 - 99 
"Declaración de los derechos del hombre y del ciudadano", el 6 de agosto de ese mismo año, ${ }^{28}$ la constitución civil del clero, que suprimió las órdenes religiosas, cuyos miembros pasaron a ser funcionarios, con lo cual se inicia el conflicto IglesiaEstado, el 12 de julio de 1790, la constitución política de 3 de septiembre de 1791, la comuna de París, la destitución del rey Luis XVII de Borbón y la convocatoria de la convención nacional, el 10 de agosto de 1792, la proclamación de la república francesa, el 20 de septiembre de 1792 y, finalmente, la ejecución de Luis XVI de Borbón (Versalles 23. VIII. 1754 - París), el 21 de enero de 1793. Todos estos acontecimientos precipitaron el movimiento reaccionario de los Borbones españoles y sus gobiernos no sólo en el ámbito político, sino también en el universitario.

\section{Extinción de las cátedras de Derecho Público, Natural y de Gentes en España y en el Nuevo Reino de Granada [Colombia] en 1794 y creación de la Cátedra de Derecho real o patrio (ius patrium)}

Mediante real orden de 31 de julio de 1794 el gobierno español suprimió las cátedras de Derecho público, del natural y de gentes en las universidades: ${ }^{29}$

Teniendo por justas las razones que me han hecho presente algunos Ministros de mi mayor confianza, y otras personas de acreditada probidad, prudencia y doctrina, he resuelto suprimir en todas las Universidades, y en todos los Seminarios y Estudios,

\footnotetext{
${ }^{28}$ El ilustrado neogranadino D. Antonio Nariño Álvarez (Santafé de Bogotá 1765 Villa de Leyva 1823) -el Precursor, le llamamos en Colombia-, hizo la traducción con base en F. M. KEVERSEAN - G. CLAVELIN, Histoire de la Revolution de 1789 et de l'établessiment d'une Constitution en France (Paris 1790) 39 - 45, en diciembre de 1793, imprimiéndola en la "Imprenta Patriótica", de su propiedad. Se difundió en la Nueva Granada, Venezuela y el Caribe. Eso contra la prohibición expresa prevista en las Circulares acordadas de 4. XII. 1789 y 5. I. 1790, en la Orden circular de 5. I. 1791 y R. C. de 10. IX. 1791, sobre "Prohibición de papeles sediciosos y contrarios a la fidelidad y tranquilidad pública". (Ed.) Cfr. M. MARTÍNEZ ALCUBILLA. (1885): Códigos Antiguos de España II, Madrid; Novísima Recopilación 8, 18,11, pp. 1593 y nn. 11 14. En julio de 1794 fue denunciado con otros ilustrados neogranadinos. Declarado reo de alta traición y condenado a diez años de prisión en África, más la confiscación de todos sus bienes. El 17 de marzo de 1796 se fugó en Cádiz, pasando a Francia e Inglaterra. De vuelta en la Nueva Granada en 1797, fue detenido nuevamente en 1803, otorgándosele la libertad vigilada por su deteriorado estado de salud. Ante el ambiente pre-revolucionario de la Nueva Granada fue conducido en 1809 a un calabozo del Palacio de la Inquisición de Cartagena de Indias, en donde estuvo recluido hasta 1810 . Vid. J. A. MEDELLÍN BECERRA - D. FAJARDO RIVERA. (2005): Diccionario de Colombia, Bogotá $s$. v. Nariño Álvarez, Antonio (Santa Fe 1765 - Villa de Leiva 1823) p. 688.

${ }^{29}$ Cfr. (Ed.) M. MARTÍNEZ ALCUBILlA, Códigos Antiguos de España II (Madrid 1885) Novísima Recopilación 4, 4, 5 p. 1528: "Estinción de las cátedras del Derecho Público, del Natural y de Gentes en las Universidades, Seminarios y Estudios. D. Carlos IV por R. O. comunicada al Consejo en 31 de julio de 1794". No hemos podido establecer si la decisión pasó -si debía pasar- también por el Supremo Consejo de Indias en relación con el Nuevo reino de Granada.
} 
las cátedras que modernamente se han establecido de Derecho Público, y del Natural y de Gentes, y la enseñanza de ellos, donde, sin haber cátedra, se hayan enseñado en la de otra asignatura. Y siendo mi ánimo se lleve a efecto la expresada supresión desde antes que empiece el próximo curso; quiero, que por el Consejo se den las órdenes correspondientes para ello a la Universidad de Granada, donde hay cátedra de Derecho Público, y a las demás donde, sin haberla, se hayan enseñado los expresados Derechos Público, Natural y de Gentes. ${ }^{30}$

En relación con la Universidad de Valencia, cuyo plan de estudios de 1786 había creado y dotado dos cátedras de Derecho público, natural y de gentes, mediante la R. O. de 25 de octubre de 1794, se destinaron a la enseñanza de la filosofía moral, siendo adscritas al claustro de Filosofía. ${ }^{31}$

En relación con los Colegios Mayores de San Bartolomé y Nuestra Señora del Rosario de Santafé de Bogotá, correspondió al virrey D. José de Ezpeleta (de 1789 a 1796) llevar a cabo el cumplimiento de esa R. O. de 31 de julio de 1794. En su Relación demando ${ }^{32}$ consigna lo siguiente:

[...] en el año anterior [1795] se ha suprimido en uno y otro [Colegio] la cátedra de derecho público, y sustituido por la de derecho real, como más propia y conveniente en las circunstancias del país y del tiempo [...]. Correspondió al rector del Colegio Mayor de Nuestra Señora del Rosario, D. Fernando Caycedo y Flórez (de 1793 a 1796 [Primer rectorado]) ${ }^{33}$ el cumplimiento de esa R. O., la cual se la comunicó el virrey en los siguientes términos:

\footnotetext{
${ }^{30}$ Cfr. (Ed.) M. MARTíNEZ ALCUBILlA, Códigos Antiguos de España II (Madrid 1885) Novísima Recopilación p. 1528 y n. 4: "Con igual fecha de 31 de julio se comunicó Real Orden a la Universidad de Valencia para que, cesando las cátedras de Derecho Público, Natural y de Gentes, expusiera sobre su subsistencia, mudándoles el nombre y la asignatura", y n. 5: "Y al mismo tiempo se comunicó otra orden a los Estudios Reales de San Isidro y Seminario de Nobles de Madrid, para que desde luego se entendiesen suprimidas las cátedras de Derecho Natural y de Gentes, sin darlos por ahora otro destino".

${ }^{31}$ Cfr. (Ed.) M. MARTÍNEZ ALCUBILlA, Códigos Antiguos de España (Madrid 1885) Novísima Recopilación 8, 5, 6 p. 1528: "Destino de las dos cátedras del Derecho Público, Natural y de gentes a la enseñanza de la Filosofía Moral en la Universidad de Valencia. El mismo [D. Carlos IV] por R. O. comunicada al Cons. En 25 de Oct. 1794". ${ }^{32}$ Cfr. (Ed.) G. HERNÁNDEZ DE ALBA. (1983): Documentos para la historia de la educación en Colombia V [1777 - 1800] N 255, Bogotá, p. 391 (- 399): De fecha Santafé de Bogotá 3 de diciembre de 1796: "La instrucción pública durante el virreinato de don José de Ezpeleta, Conde de Veire". Vid. R. SILVA. (2002): Los ilustrados de Nueva Granada 1760 - 1808. Genealogía de una comunidad de interpretación. Medellín, pp. $82-83$.

${ }^{33}$ Vid. Ma . C. GUILLÉN DE IRIARTE, Rectores y rectorías del Colegio Mayor de Nuestra Señora del Rosario 1653 - 2003 (Bogotá 2003) s. v. Fernando de Caycedo y Flórez (1756 - 1832) 303 - 324, concretamente en p. 318 y n. 1329.
}

Rhela. Vol. 14. Año 2010, pp. 83 - 99 
[...] no resultando de utilidad alguna a la juventud de este reino de la cátedra de derecho natural y de gentes establecida en ese Colegio, dispondrá vuestra merced se sustituya a ella la de leyes del reino.

Téngase en cuenta que en el plan de Moreno y Escandón de 1774, el Derecho real o patrio (ius patrium) se estudiaba a propósito del Derecho romano por falta de recursos para dotar una cátedra propia. Así, pues, correspondió al mencionado virrey Ezpeleta la creación - con base en la supresión de la cátedra de Derecho público, natural y de gentes, creada y dotada en la reforma de 1779- y dotación- con los haberes de la extinguida- de la mencionada cátedra de Derecho real o patrio en 1795.

Así, pues, en nuestra opinión, debe ser debidamente matizada la opinión según la cual "La reforma que tuvo lugar en España en 1780, consistente en crear cátedras universitarias de derecho real no llegó a ser implantada en Indias. Lo propio ocurrió con aquella otra reforma de 1770, de crear cursos de derecho natural y de gentes, aunque aquella propiamente no tuvo lugar en la universidad." ${ }^{34}$

\section{Juristas Ilustrados Neogranadinos e Independencia de Colombia}

Sean estas páginas un modesto homenaje a la generación de juristas ilustrados neogranadinos que cayeron -fusilados- en la dura guerra de independencia de Colombia de la madre patria. Tuvieron su formación académica - la mayor parte de ellos- bajo el plan de estudios de jurisprudencia de F. A. Moreno y Escandón (1774) - J. F. Gutiérrez de Piñeres (1779). Fueron los siguientes:

1. Álvarez y Casal, Manuel Bernadro (Bogotá 1743 - 1816)

2. Ardila Antonio (Socorro - Bogotá 1816) ${ }^{35}$

3. Armero, José León (Mariquita 1786 - Bogotá 1816)

4. Ayos Elejalde, Antonio José (Cartagena de Indias - 24. II. 1816)

5. Benítez Plata, Emigdio (Socorro 1766 - Bogotá 1816)

6. Caycedo de la Hera, Francisco Antonio (Santiago de Cali 1765-Bogotá 1816) ${ }^{37}$

7. Caycedo y Cuero, Felipe Joaquín (Santiago de Cali 1773 - Bogotá 1816)

8. Camacho Rodríguez, José Joaquín (Tunja 1766 - Bogotá 1816)

\footnotetext{
${ }^{34}$ Vid. A. GUZMÁN BRITO, La codificación civil en Iberoamérica. Siglos XIX y XX (Santiago de Chile [Editorial Jurídica de Chile] 2000) 163 y n. 313.

${ }^{35} \mathrm{M}^{\mathrm{a}} \mathrm{C}$. GUILLÉN DE IRIARTE, Colegio Mayor de Nuestra Señora del Rosario 1651 1820 II (Bogotá 1994) No 835 p. 561: Vistió el manto de familiar el 6 de febrero de 1792.

${ }^{36} \mathrm{M}^{\mathrm{a}}$. C. GUILLÉN DE IRIARTE, Colegio Mayor de Nuestra Señora del Rosario 1651 1820 II (Bogotá 1994) N 697 p. 482: 1782, colegial convictor.

${ }^{37}$ (Dir.) W. JARAMILLO MEJ́A, Real Colegio Mayor y Seminario de San Bartolomé 1605

- 1820 (Bogotá 1996) Nº 1549 p. 601: Presentó informaciones el 27 de agosto de 1783.
} 
9. Cañete, Manuel (Cúcuta - Bogotá 1816)

10. Castillo, Manuel (Cartagena de Indias 1781 - Bogotá 1816)

11. Dávila, José María (Rionegro - Bogotá 1816)

12. Díaz Granados, Miguel (Cartagena de Indias 1772 - Bogotá 1816) $)^{38}$

13. García de Toledo, José María (Cartagena de Indias 1769 - Bogotá 1816)

14. García Rovira, Custodio (Bucaramanga 1780 - Bogotá 1816) ${ }^{39}$

15. Gutiérrez, Frutos Joaquín (Cúcuta 1770 - Bogotá 1816) ${ }^{40}$

16. Gutiérrez Moreno, José Gregorio (Bogotá 1781 - 1816)

17. Hoyos, Joaquín de (Antioquia 1773 - Bogotá 1816) ${ }^{41}$

18. Lombana Cuervo, Joaquín María (Bogotá 1781 - 1816)

19. López de tagle, Juan Elias (Cartagena de Indias 1777 - Bogotá 1819)

20. Matey de Pedri, Juan Nepomuceno (Cúcuta 1766 - Bogotá 1816) (2 $^{42}$

21. Niño, Juan Nepomuceno (Tunja - Bogotá 1816) ${ }^{43}$

22. Peña y Valencia, José Gabriel (Pamplona - Bogotá 1816) ${ }^{44}$

23. Pombo Pombo, Miguel (Popayán - Bogotá 1816)

24. Torres y tenorio, Camilo (Popayán 1766 - Bogotá 1816) ${ }^{46}$

25. Uñana López, Joaquín (Tunja 1768 - Bogotá 1816) ${ }^{47}$

26. Ulloa Campos, Francisco Antonio (Popayán 1766 - Bogotá 1816) ${ }^{48}$

27. Vargas, Ignacio de (Charalá 1771 - Bogotá 1816) ${ }^{49}$

28. Vázquez, José Cayetano (Tunja 1771 - Bogotá 1816)

${ }^{38} \mathrm{M}^{a}$. C. GUILLÉN DE IRIARTE, Colegio Mayor de Nuestra Señora del Rosario 1651 1820 II (Bogotá 1994) No 722 p. 495: Vistió la beca en 1784.

${ }^{39}$ (Dir.) W. JARAMILLO MEJ́́A, Real Colegio Mayor y Seminario de San Bartolomé 1605

- 1820 (Bogotá 1996) $\mathrm{N}^{\circ} 1816$ p. 723: Presentó informaciones el 23 de junio de 1796.

${ }^{40}$ (Dir.) W. JARAMILLO MEJÍA, Real Colegio Mayor y Seminario de San Bartolomé 1605 - 1820 (Bogotá 1996) № 1570 p. 609: Presentó informaciones el 15 de julio de 1784.

${ }^{41}$ (Dir.) W. JARAMILLO MEJIA, Real Colegio Mayor y Seminario de San Bartolomé $1605-1820$ (Bogotá 1996) $\mathrm{N}^{\circ} 1638$ p. 636: Presentó informaciones el 16 de octubre de 1787.

42 (Dir.) W. JARAMILLO MEJÍA, Real Colegio Mayor y Seminario de San Bartolomé 1605 - 1820 (Bogotá 1996) No 1576 p. 612: Presentó informaciones el 7 de octubre de 1784.

${ }^{43} \mathrm{M}^{\mathrm{a}}$. C. GUILLÉN DE IRIARTE, Colegio Mayor de Nuestra Señora del Rosario 1651 1820 II (Bogotá 1994) No 712 p. 490: Vistió la beca el 11 de febrero de 1783.

${ }^{44} \mathrm{M}^{\mathrm{a}}$. C. GUILLÉN DE IRIARTE, Colegio Mayor de Nuestra Señora del Rosario 1651 1820 II (Bogotá 1994) No 818 p. 553: Vistió la beca el 31 de octubre de 1790.

${ }^{45}$ Ma. C. GUILLÉN DE IRIARTE, Colegio Mayor de Nuestra Señora del Rosario 1651 1820 II (Bogotá 1994) № 918 p. 608: Vistió la beca el 3 de diciembre de 1797.

${ }^{46} \mathrm{M}^{\mathrm{a}}$. C. GUILLÉN DE IRIARTE, Colegio Mayor de Nuestra Señora del Rosario 1651 1820 II (Bogotá 1994) No 792 p. 539: Vistió la beca el 17 de diciembre de 1788.

${ }^{47}$ (Dir.) W. JARAMILLO MEJÍA, Real Colegio Mayor y Seminario de San Bartolomé 1605

- 1820 (Bogotá 1996) N 1588 p. 617: Presentó informaciones el 1 de febrero de 1785.

${ }^{48} \mathrm{M}^{\mathrm{a}}$. C. GUILLÉN DE IRIARTE, Colegio Mayor de Nuestra Señora del Rosario 1651 1820 II (Bogotá 1994) No 792 p. 622: Vistió la beca el 5 de noviembre de 1800.

49 (Dir.) W. JARAMILLO MEJ́A, Real Colegio Mayor y Seminario de San Bartolomé 1605

- 1820 (Bogotá 1996) No 1628 p. 632: Presentó informaciones el 4 de octubre de 1787.

${ }^{50} \mathrm{M}^{\mathrm{a}}$. C. GUILLÉN DE IRIARTE, Colegio Mayor de Nuestra Señora del Rosario 1651 1820 II (Bogotá 1994) No 710 p. 489: Vistió la beca el 19 de diciembre de 1782. 
El homenaje más merecido a esta generación de universitarios neogranadinos ilustrados, cuya pérdida habría de resultar de las más nefastas consecuencias para el desarrollo político posterior de la nación colombiana, está en boca del comandante en jefe del ejército de la "reconquista", D. Pablo Morillo (Fuenteseca [Zamora] 5. V. 1778 - Borges [Francia] 27. VII. 1837). En efecto, después del sitio de Cartagena de Indias (19. VIII - XII. 1815), en la relación de prisioneros que el general Morillo pasó al capitán general y virrey D. Francisco de Montalvo, se lee lo siguiente ${ }^{51}$ : "José Ayos.- Este individuo ha sido más perjudicial a la causa del rey que si hubiese sido general de los rebeldes, y seguía su sistema con el mayor entusiasmo; y tanto por sus escritos como por sus disposiciones, son notorios sus crímenes."

\section{CONCLUSIÓN}

La reforma del intendente D. Juan Francisco Gutiérrez de Piñeres de 1779 al plan de estudios del fiscal D. Francisco Antonio Moreno y Escandón de 1774 fue involutiva, excepto para el plan de estudios de jurisprudencia que, manteniendo el mismo de 1774 introdujo, además, la cátedra de Derecho público, natural y de gentes. 2. Con ese plan de jurisprudencia se formó la dirigencia jurídico política de primera línea de la independencia nacional. Desgraciadamente la mayor parte de ellos cayeron fusilados en 1816.

\section{REFERENCIAS}

BETANCOURT SERNA, Fernando. (2007): La recepción del derecho romano en Colombia. Sevilla.

BOTEROBERNAL. (2006): Orígenes del constitucionalismo colombiano. Medellín.

CORTÉS FALLA. (2003): La enseñanza del derecho romano en Colombia 1710 - 1826. Nueva Granada y orígenes de la República, Bucaramanga, 5. (Ed.).

G. KLEINHEYER - J. SCHRÖDER. (1996): Deutschland und europäische Juristen (Heidelberg, en Diccionario de Colombia 8, MEDELLÍN BECERRA- D. FAJARDO RIVERA, Bogotá.

OLAVIDE, Pablo de. (1989): Plan de estudios universitarios [1769], en Plan es estudios para la Universidad de Sevilla, F. AGUILAR PIÑAL; Estudio preliminar por AGUILAR PIÑA

${ }^{51}$ Vid. F. BETANCOURT SERNA - I. G. CHAVES, Don Antonio José de Ayos y la recepción del derecho romano en Colombia (Saec. XVIII), en Revista de Estudios SocioJurídicos IX 1 (Bogotá [Universidad del Rosario] 2007) $13-68$, concretamente en p. 64 n. 157. 
Francisco. $2^{\mathrm{a}}$ edición, revisada y actualizada (Sevilla 71 - 156, y en J. MARCHENA FERNÁNDEZ, Juan. (2001) El tiempo ilustrado de Pablo de Olavide. Vida, obra y sueños de un americano en la España del siglo XVIII. Sevilla.

MORENOY ESCANDÓN, Francisco Antonio. Método provisional e interino [1774], en Documentos para la historia de la educación en Colombia. Tomo IV [1767 - 1776], G. HERNÁNDEZDE ALBA, Bogotá.

SOTO ARANGO, Diana. (2004): La reforma del plan de estudios del fiscal Moreno y Escandon 1774 - 1779. Bogotá, Index librorum prohibitorum I - II (Matriti 1707). 4. (Ed.)

M. MARTÍNEZ ALCUBILLA. (1885): Códigos Antiguos de España I- II, Madrid.

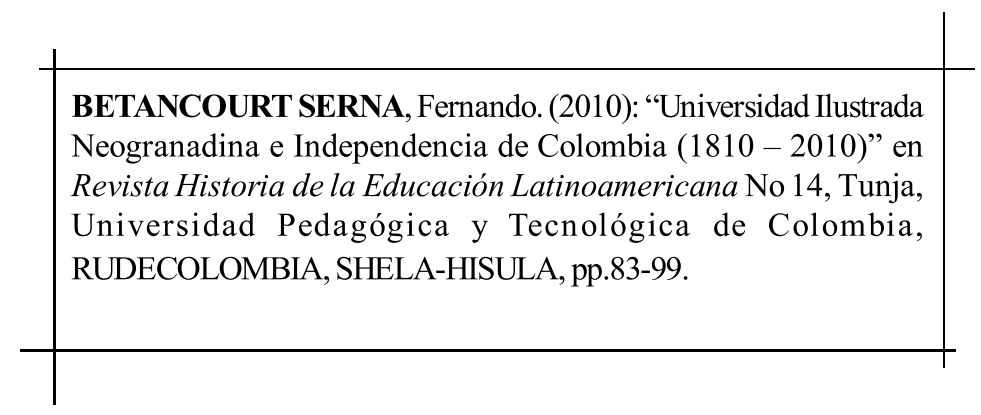

Rhela. Vol. 14. Año 2010, pp. 83 - 99 